DOI 10.37882/2500-3682.2021.02.11

\title{
СИСТЕМА ОБРАЗОВАНИЯ - УРОВЕНЬ И КАЧЕСТВО ЧЕЛОВЕЧЕСКОГО КАПИТАЛА
}

\section{EDUCATION SYSTEM - LEVEL AND QUALITY OF HUMAN CAPITAL \\ G. Kulzhanova}

Summary: The article considers the education system as the main sphere that determines the level and quality of human capital. The relevance of the issue under study is due to the fact that the problems of education act as a key factor in the formation and development of human capital in society. The author substantiates the idea that the modernization of the education system is currently a priority task of educational policy. The method of system analysis used made it possible to establish the relationship and interdependence of the concept of human capital and the information society. The author of the article notes that human capital is an issue that requires serious attention due to the profound impact of the pandemic on people's health and education.

Keywords: human capital, knowledge society, education, human, distance learning, modernization, pandemic.
Кульжанова Гульбарам Тимеркановна

К.ф.н., дочент, Костанайская академия МВД РК имени шракбека Кабылбаева, г. Костанай, Республика Казахстан Gulbaram2012@mail.ru

Аннотация: В статье рассматривается система образования как основная сфера, определяющая уровень и качество человеческого капитала. Актуальность исследуемого вопроса обусловлена тем, что проблемы образования выступают как ключевой фактор формирования и развития человеческого капитала в социуме. Обосновывается мысль, что модернизация системы образования является на сегодняшний день приоритетной задачей образовательной политики. Используемый метод системного анализа позволил установить взаимосвязь и взаимозависимость концепции человеческого капитала и информационного общества. Автор в статье отмечает, что человеческий капитал - это вопрос, требующий серьезного внимания ввиду глубокого воздействия пандемии на здоровье и образование людей.

Ключевые слова: человеческий капитал, общество знаний, образование, человек, дистанционное обучение, модернизация, пандемия.

ского капитала, которое способно сформировать новые варианты поведения людей при получении необходимых знаний, формировании требуемых профессиональных компетенций [1, с. 224].

Для философии огромное значение приобретает то обстоятельство, что постиндустриальное общество в некоторых отношениях становится и «постэкономическим». Следовательно, наряду с сектором производства материальных благ и услуг, в огромной мере расширяется сектор «производства человека». Это ранее «третичный» сектор приобретает равноправное, а в ряде отношений и доминирующее значение. Духовное производство в этих обстоятельствах становится все более определяющим началом в совокупном производстве, подчиняя его структуру, содержание и динамику. Этот вид производства все более поворачивается в сторону «человеческого фактора», который становится и целью, и ведущим компонентом. Разрастание сферы «производства человека» приводит к далеко идущей трансформации самого типа совокупного производства. Социокультурные факторы как интеллектуальный, творческий и социальный потенциал личности в приоритетной сфере выходят на передний план. Происходит перераспределение расходов на материальное производство в пользу науки, образования, здравоохранения и социального обеспечения. Для успешного формирования и развития человеческого капитала нужны более серьезные обще- 
ственные усилия. Немецкий учёный Герберт Маркузе в своем труде «Одномерный человек» акцентировал внимание на то, что необходимо найти тот правильный путь, при котором использование и материального, и человеческого капитала позволяло бы наиболее оптимально развивать и удовлетворять потребности и способности людей при минимуме тяжелого труда и бедности [2]. Параметры жизнедеятельности человека, возможности его собственного развития и самореализации соответствуют структуре экономики и задачам общества. А социальная и образовательная политика являются основами и критериями успешного формирования, применения и накопления человеческого капитала.

Инновационное развитие всего нашего общественного целого требует колоссальных инвестиций в качественную подготовку и развитие собственного человеческого капитала. В особенности, в настоящий момент, человеческий капитал является социально-философской проблемой, требующей фундаментального анализа ввиду глубокого воздействия пандемии на здоровье и образование людей. В этом случае, разделяем точку зрения Р.К. Турысжановой, А. Рамазановой, Ж. Амиркуловой - авторов статьи «Инновации в образовании и формирование человеческого капитала». Они в свой работе приходят к мнению, что своевременность и актуальность социально-философского анализа повседневного образовательного процесса объясняется тем, что создаваемые теоретические концепции, идеальные модели, планируемые законы и реформы в сфере образования, воплощаются в конкретных социальных практиках. Считают, что анализ этих практик позволяет понять глубинные основания постоянного воспроизводства одних и тех же проблем и противоречий в деятельности образовательных учреждений, закономерности формирования и изменения критериев образованности [3, с. 57].

Центральные направления модернизации образования - повышение качества и эффективности образования, обеспечение его непрерывности, рост социальной мобильности молодежи. Это делают систему образования важным двигателем социально-экономического развития страны, источником роста ее человеческого капитала. Проведенный сравнительный анализ Ю.В. Астаховой позволил выявить некоторые проблемы образования как ключевые факторы формирования и развития человеческого капитала. На основе исследования автору удалось установить, что уровень развития страны напрямую зависит как от уровня и разносторонности общего образования основной массы населения, так и от качества подготовки специалистов в средней и высшей школе [4, с. 10].

Исследователь В.А. Михеев в своей работе рассматривает содержание понятия «человеческий капитал», контуры инклюзивной политики развития человеческо- го капитала, пути его роста на основе сотрудничества государства, бизнеса и гражданского общества, анализируются барьеры в реализации этой деятельности. Инклюзия (от лат. - включение, включать, Включаться) - это процесс включенности, участия в конкретной деятельности, в политике, позволяющий индивиду, социальным группам, слоям равноправно участвовать в общественной жизни, в принятии решений. Содержание указанного понятия рассматривается как исключительно подвижная субстанция, обладающая эвристической ценностью. Как благо длительного пользования, может устаревать, снижаться в зависимости от изменений социально-экономических, производственных факторов, спроса и потребления. Как следствие, он является благом не только для индивида, но и для социальных групп, слоев, отдельных хозяйствующих управленческих структур, для государства и общества в целом [5, с. 32].

Особую актуальность с недавних пор обретают комплексные исследования, которые проводятся с целью изучения тенденций формирования и эффективного использования человеческого капитала. Российские учёные Е. А. Пришляк, С.Г. Радько подчеркивают, что важным фактором, влияющим на формирование человеческого капитала, является развитие образования в стране. Оно позволяет сформировать определенный запас знаний, который оптимально и рационально используется в трудовой деятельности человека. Как правило, постоянно пополняемый запас знаний и умений, является источником стабильного и даже увеличивающегося дохода. На сегодняшний день достаточно востребованы специалисты, как с высшим, так и со средним профессиональным образованием [6, с. 100].

В контексте формирования единого глобального информационного социума уместно упомянуть концепцию человеческого капитала. Благодаря развитию информационных технологий в середине XX века наша планета превратилась в единый населенный пункт, где границы становятся условными, а реальными становятся виртуальные безграничные пространства коммуникации. В этих условиях происходят серьезные трансформации человека как личности и его сознания. Человеческий капитал является базовым активом, благодаря которому граждане становятся продуктивными членами общества и создают возможности для процветания своих стран. Пандемия коронавирусной инфекции COVID-19 нанесла удар по этому ценному активу. В отличие от стихийных бедствий, чье разрушительное воздействие на физический капитал намного превосходит воздействие на человеческий. Пандемия оставила нетронутыми здания, заводы и инфраструктуру, но при этом крайне негативно отразилась на здоровье миллионов людей и сорвала обучение миллионов детей. С учетом характера последствий пандемии правительства рассматривают инвестиции в человеческий капитал как один из центральных 
элементов своих планов по восстановлению экономики [7, c. 47].

В марте 2020 года почти все страны мира полностью закрыли все учреждения своих систем образования, пытаясь, таким образом, увеличить социальное дистанцирование и предотвратить распространение инфекции. Судя по эпидемиологическим данным, закрытие образовательных учреждений действительно помогло сократить распространение инфекции. Авторы доклада «Всемирного банка, 2020 год. «COVID-19 и человеческий капитал» указывают, что пандемия со всей очевидностью показала, что в периоды кризиса возможен значительный рост неравенства в доступе к качественному образованию. Дистанционное обучение, ставшее необходимостью в результате пандемии, поставило сложную задачу и перед учителями, которые не всегда обладали нужными навыками для такой формы обучения, и перед учащимися, у которых не всегда был доступ к цифровым технологиям, необходимым для онлайн обучения. Следует отметить, что закрытие школ привело к потерям в образовании даже в тех случаях, когда организовывалось обучение в альтернативной форме. Их закрытие стало особенно пагубным для детей из социально незащищенных семей. К тому же, сегодняшние рынки труда требуют более высокого уровня развития человеческого капитала, чем в прошлом. Поэтому наличие надежного фундамента становится все более существенным, поскольку основного образования будет недостаточно.

Сегодня государственные органы и образовательные учреждения делают все возможное для того, чтобы минимизировать последствия закрытия школ, обеспечивая возможности для перехода на традиционное обучение. Между странами мира были большие различия по уровню готовности к переходу на дистанционное обучение. Переход на онлайн обучение осуществлялось в экстренном порядке.

Однако сейчас становится все более очевидным то, что дистанционное обучение отличается от очного значительно более выраженным неравенством возможностей. Это связано с тем, что в данном случае важную роль играют такие характеристики домохозяйств, как наличие интернета и необходимых технических средств, а также присутствие членов семьи, которые могли бы оказывать детям помощь во время занятий. Таким образом, пандемия может, в итоге, привести не только к снижению средних показателей успеваемости, но и к росту неравенства по образовательным результатам. В условиях сложившейся эпидемиологической ситуации были выдвинуты основные задачи, которые нужно было решать в ускоренных темпах для продолжения образовательного процесса. В первую очередь, обеспечение всех обучающихся техническими средствами и возможностью подключения к тем каналам связи, которые им необходимы для полноценного дистанционного обучения. Следующая задача состояла и состоит в повышении качества дистанционного обучения, в целом, в модернизации системы основного общего образования.

Результатом образовательного процесса должно стать не знание само по себе, а знающий человек, личность. Ведь «образование - это не только и даже не столько трансляция информации (пусть даже самой ценной, самой полезной для становления личности), не только и даже не столько апелляция к интеллекту (хотя отрицать это просто бессмысленно), сколько апелляция к чувствам, к индивидуально неповторимому внутреннему миру человека» [8, с.342]. Из этого следует, что современный образованный человек, конечно, должен иметь хорошие знания в своей области деятельности, определенную квалификацию, кругозор, эрудицию. Но не это будет определять степень его образованности. Это должен быть человек с развитым внутренним миром, духовно зрелый, нравственный, ответственный, истинный гражданин своего отечества.

\section{Зак^ючение}

Таким образом, главная задача, стоящая перед человечеством в XXI веке - улучшение качества жизни, в том числе и образования, определяющего условия развития личности и общества. Успехи государств определяются, прежде всего, человеческим фактором, интеллектуальным потенциалом граждан страны. В условиях индустриально-информационного общества в качестве основных факторов выступают конкурентоспособность, целесообразность, темпы инновации в технологиях. В совокупности, всё в большей мере зависит от состояния знаний и интеллектуальных способностей. Именно поэтому реформирование и совершенствование системы образования является определяющим фактором решения большинства проблем в условиях глобализации современного общества.

\section{ЛИТЕРАТУРА}

1. Алайцева Т.В. Человеческий капитал и система национального образования // Вестник Самарского государственного университета. Серия «Экономика и управление». 2015. № 9/1 (131). С. 224-229

2. Маркузе Г. Одномерный человек. M.: REFL-Book, 1994

3. Турысжанова Р.К., Рамазанова А., Амиркулова Ж. Инновации в образовании и формирование человеческого капитала // Международный научно-иссле- 
довательский журнал, 2015 г. №3 (34) Часть 2. С. 56-58

4. Астахова Ю.В. Проблемы формирования человеческого капитала в условиях модернизации российского образования // Международный научно-исследовательский журнал, 2015 г. №6 (37) Часть 3. С. 6-11

5. Михеев В.А. Инклюзивная политика человеческого капитала // Власть, 2018. Том 26. № 1. С. 30-36.

6. Пришляк Е. А., Радько С. Г. Исследование факторов, влияющих на формирование человеческого капитала в Российской Федерации // Управленческие науки, 2018. Т.8 №2. С.94-105

7. Всемирный банк, 2020 год. “COVID-19 и человеческий капитал»”. Доклад об экономике региона Европы и Центральной Азии, осень 2020 года. Всемирный банк, Вашингтон, округ Колумбия.

8. Гершунский Б.С. Философия образования. - Москва: Флинта, 2002. - 432 с.

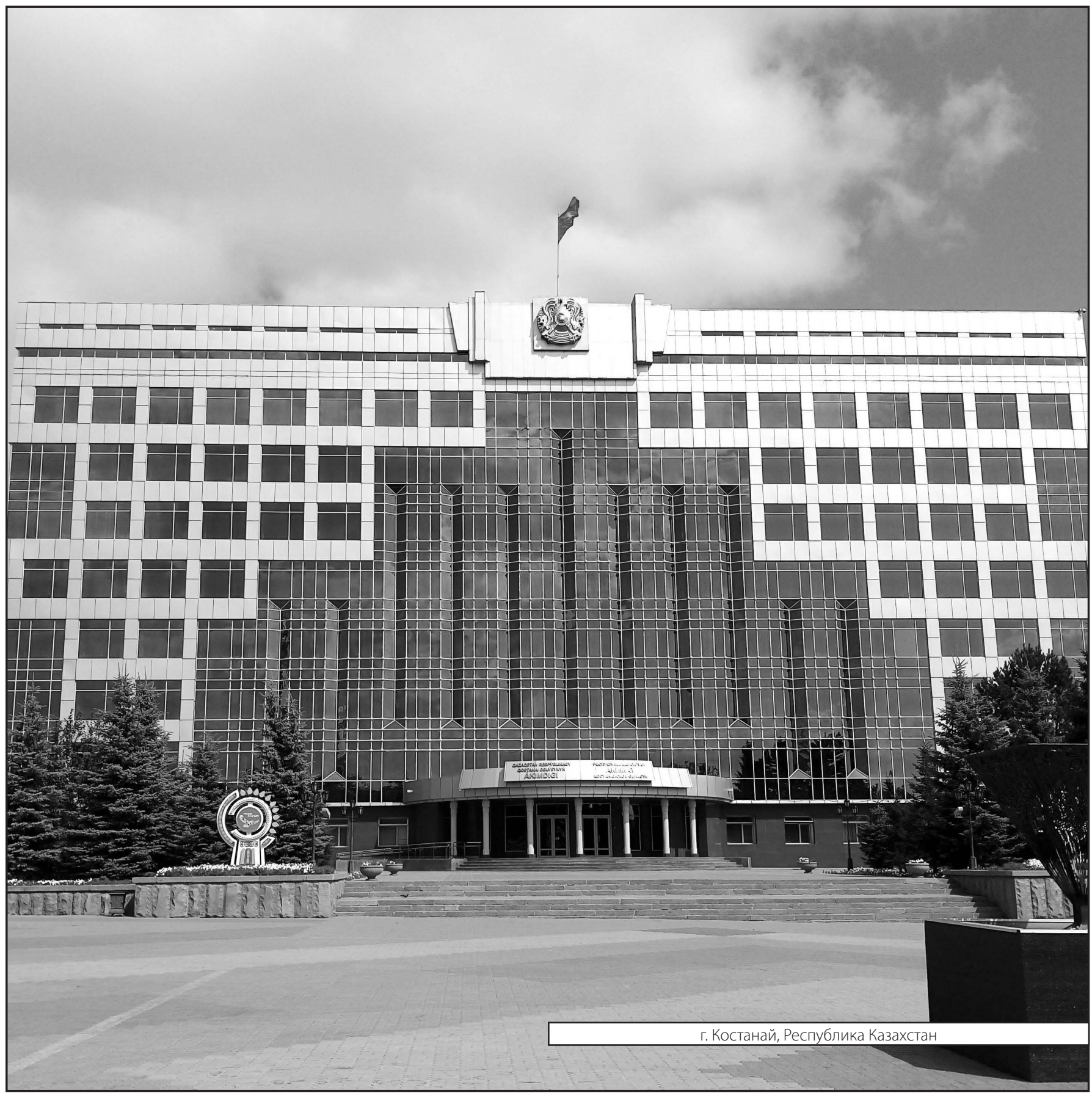

